\title{
Intensidade e duração de formas reduzidas no português brasileiro
}

\author{
Larissa Santos Ciríaco \\ Bolsista do CNPq \\ Lorenzo Teixeira Vitral \\ Universidade Federal de Minas Gerais \\ César Reis \\ Universidade Federal de Minas Gerais
}

\section{Abstract}

In Brazilian Portuguese reduction occurs in some pronouns, for instance, cê (from você); el and ez(from the pronouns ele and eles); num (from não) and others that have been analyzed as becoming clitics (VITRAL \& RAMOS, 2002). In order to prove this hypothesis, we collected a corpus with almost 500 utterances containing the reduced forms above. The reduced forms were acoustically analyzed considering the intensity and duration parameters and then compared with those parameters of real clitics. This paper presents the research results and the conclusions we have achieved in this work. 


\section{INTRODUÇÃO}

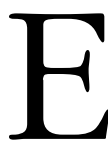

ste trabalho visa investigar o comportamento acústico de algumas formas reduzidas do português brasileiro, a saber: Cê(redução de você), $E z$ (redução de eles) e Num (redução de não).

Em Vitral (1996), a primeira dessas partículas, isto é, Cê, foi avaliada como um clítico. O estatuto de clítico foi também estendido às partículas Ez e Num em Vitral (1999), Ramos (1997) e Corrêa (1998). A hipótese de Vitral (1996) está baseada no comportamento sintático de Cê, ou seja, a atribuição de clítico para as formas reduzidas é motivada por uma distribuição sintática dessas partículas. De acordo com esse autor, a partícula $C \hat{e}$, assim como os clíticos pronominais do português brasileiro, não pode ser encontrada nos seguintes ambientes: como tópico, como exemplificado em (1), modificados por um advérbio, como em (2), sem um hospedeiro no qual se possa ancorar, como em (3), como complemento de preposição, como em (4) e nem como elemento coordenado a uma forma tônica, como em (5). Os exemplos de (1) a (5) correspondentes à distribuição acima foram retirados de Vitral (1996) e são os que se seguem:

1)*Cê, ele não viu.

2)*Só cê não consegue emprego.

3)*Eu amo cê. / Quem ganhou? *Cê.

4)*Eu trouxe pra cê.

5)*Ele e cê podem votar contra.

A proposta de que Cêe um clítico é ainda corroborada pela análise de Vitral (no prelo), na qual são investigadas duas propriedades acústicas de Cê, a saber: a duração e a intensidade. Nesse trabalho, o autor mostra-nos que os valores da intensidade e da duração de Cêsão menores do que os encontrados para o monossílabo Zé, e são 
maiores do que os identificados para o clítico pronominal Se. Haveria, assim, uma gradação de valores para esses parâmetros, o que atestaria o caráter reduzido da forma $C \hat{e}$. Esses resultados levaram o autor a reformular sua hipótese inicial e a propor que Cê não é ainda um clítico pleno, mas se encontra em um processo de cliticização.

Neste trabalho, pretende-se desenvolver a metodologia proposta por Vitral, evitando certas deficiências encontradas, e estender sua perspectiva de análise para as demais formas reduzidas mencionadas, ou seja, Eze Num. Aqui, trabalharemos, primeiramente, com a hipótese de que as reduções mencionadas podem ser atestadas foneticamente, e, posteriormente, que existe para elas um processo de cliticização e que esse processo pode ser constatado através da análise acústica.

O trabalho é estruturado da seguinte maneira: no item 2 forneceremos uma breve descrição do experimento; no item 3 falaremos dos parâmetros de análise acústica dos quais nos servimos e dos valores para esses parâmetros obtidos com a análise; a parte final trata das conclusões que o embasamento teórico e a análise nos permitem considerar.

\section{OS PROCEDIMENTOS PARA A COLETA DE DADOS}

Os dados deste estudo foram editados com o programa Sound Designer II e analisados através do programa de análise acústica Macquirer. Porém, antes da análise, estudamos uma maneira que permitisse a coleta adequada das formas reduzidas. Sabíamos que partir de dados de fala espontânea seria inviável, visto que a pesquisa tem por objetivo o comportamento fonético das partículas reduzidas, o que acarreta a observância do contexto fonético em que ocorrem as realizações dos segmentos. Por isso, desenvolvemos um experimento composto de treze sentenças cuidadosamente escolhidas, observandose os contextos e as propriedades fonéticas de duração total, ritmo e acento das mesmas.

O experimento foi realizado com quatro informantes, sendo dois de cada sexo, todos estudantes do primeiro período do curso 
de Letras da Universidade Federal de Minas Gerais, com idade entre 18 e 21 anos e nascidos e desde sempre habitantes da cidade de Belo Horizonte, Minas Gerais ${ }^{1}$. As gravações foram feitas em cabine acusticamente tratada, no Laboratório de Fonética da Faculdade de Letras da UFMG e utilizando-se de gravador digital. Cada informante fez três leituras das treze sentenças sendo que seis das sentenças eram pronunciadas três vezes a cada leitura, ou seja, seis das sentenças foram realizadas nove vezes cada uma por cada informante em três velocidades de fala diferentes, a saber: normal, rápido e rapidíssimo. As sete sentenças restantes foram pronunciadas apenas uma vez a cada leitura, ou seja, três vezes cada uma por cada informante, sem a utilização do recurso da velocidade.Vale ressaltar que não houve comparação entre as partículas para as quais utilizou-se do recurso da velocidade e aquelas para as quais esse recurso não foi utilizado, a comparação deu-se entre formas plenas e respectivas formas reduzidas, como entre Eles e Ez, por exemplo. Desse modo, nosso corpus é composto por 75 realizações das sentenças por cada informante, totalizando 300 realizações.

O recurso de velocidade foi utilizado a fim de se obter a produção das formas reduzidas Eze Num. As três velocidades de fala utilizadas eram normal, rápida e rapidíssima e não lenta, normal e rápida, como era de se supor, porque com isso obteríamos as reduções com segurança. Com esse recurso pudemos obter as formas reduzidas, mesmo tendo nas frases escritas as formas ortográficas Eles e Não. A forma reduzida $E z$ foi obtida principalmente na velocidade rapidíssima, ocorrendo também algumas vezes na velocidade rápida e outras poucas na velocidade normal. A redução Num ocorreu facilmente na velocidade rapidíssima e algumas vezes nas velocidades normal e rápida. Também fazia parte do conjunto das seis frases pronunciadas com o emprego da velocidade a forma $E x^{2}$, (como em ex-marido ou ex-mulher). As sete sentenças restantes continham o clítico $S e$ e a ocorrência de $C \hat{E}$ (grafado aqui completamente em caixa alta para distinguirmos-lo de Cê, redução de você) como referência a nome próprio. Para isso, nossos informantes foram instruídos de 
que $C \hat{E}$ seria o apelido do nome Cecilia. Assim, ao serem pronunciadas as sentenças que continham essa partícula, os informantes o faziam tendo em mente que estavam se referindo a um nome próprio e não a um pronome de tratamento, como quando pronunciavam o $C \hat{e}$ enquanto forma reduzida de você. A redução de você foi escrita normalmente no experimento, em sua forma ortográfica $C \hat{e}$, por ser um segmento mais difundido no falar mineiro e por já não causar estranheza ao ser lido (em linguagem de internet, por exemplo, o uso de Cê escrito já é bem comum). Portanto, também fazia parte de nosso propósito a preocupação de que as realizações de nossas sentenças fossem o mais naturais possível, embora produzidas em laboratório. Para nos aproximarmos da fala espontânea, pedíamos que as frases fossem guardadas rapidamente na memória antes de serem pronunciadas, ou seja, nosso intuito era o de que o informante não ficasse preso à leitura. As sentenças do experimento são as que se seguem³:

1. Diga Cê disse que Zé vai viajar. (Cê =Cecília)

2. Diga eles falou que Zé vai viajar.

3. Diga Jô não disse nada não.

4. Diga cê disse que Zé vai viajar. (cê = pronome)

5. Diga cê falou que Zé vai viajar. (cê = pronome)

6. Diga o estilista vestiu $C \hat{e}$ bem. (Cê =Cecília)

7. Diga eles disse que Zé vai viajar.

8. Diga o estilista vestiu-se bem.

9. Diga Cê falou que Zé vai viajar. (Cê =Cecília)

10. Diga Jô não falou nada não.

11. Diga o estilista vestiu cê bem. (cê = pronome)

12. Diga ex diz muita coisa.

13. Diga eles diz muita coisa.

Após a coleta dos dados e observados todos esses procedimentos acima citados, realizamos a edição e, posteriormente, a análise acústica dos segmentos em estudo. 


\section{ANÁLISE ACÚSTICA}

A análise espectrográfica dos segmentos de nosso corpus nos permitiu medir os valores para os parâmetros de intensidade e duração. Utilizamo-nos destes parâmetros porque, em Moraes (1995) e em Fernandes (1976), foram estudados os correlatos acústicos do acento lexical, atestando a duração e a intensidade como marcas do acento. A duração foi considerada o parâmetro mais consistentemente presente como correlato do acento primário. Nossos estudos baseiam-se na hipótese, como dissemos, de que as formas reduzidas Cê, Num e Ez, devido aos indícios sintáticos, estariam em processo de cliticização. Sendo clíticos partículas átonas, buscamos assim investigar os valores de alguns desses parâmetros das marcas acentuais a fim de averiguar os indícios fonéticos desse processo de cliticização.

A análise é baseada nos valores obtidos das medições da intensidade da duração das três formas reduzidas Cê, Num e Ez; das formas plenas Eles e Não; e da forma livre Ex. Também fazem parte de nossa análise o clítico $S E$ e a realização de $C \hat{E}$ como nome próprio (apelido de Cecília). Após as medições, comparamos os valores de $C \hat{E}$ com os valores de $C \hat{e}$ (redução de "você") e de $S e$ (clítico); os valores de Não e de Num e os valores de Eles, com os de $E x$ e de $E z$.

Todas essas partículas acima ocupavam os seguintes ambientes nas sentenças: antes de sílaba tônica, isto é, antes de disse ou diz, como em 1, 3, 4, 7,12 e 13; antes de sílaba átona, isto é, antes de falou, como em 2, 5, 9 e 10 e como elemento pós verbal ${ }^{4}$ para as formas Cê (pronome), ChE (apelido de Cecília) e Se (pronome reflexivo), isto é, nas sentenças 6,8 e 11.

Após o cálculo das médias das ocorrências das formas clíticas e plenas, nas três velocidades, no caso das formas para as quais esse recurso foi utilizado, os resultados obtidos para a duração, em milésimos de segundos (ms), e para a intensidade, em decibéis (dB) nos ambientes fonológicos descritos acima, são os mostrados na Tabela 1 abaixo. Essa tabela está assim representada: cada grupo corresponde a uma etapa de comparação. Assim, o grupo 1 refere- 
se às realizações de Eles, $E z$ e $E x$; o grupo 2 refere-se às realizações de Não e Num; o grupo 3 às realizações de $C \hat{E}$ e de $C \hat{e}$ antes de verbo e o grupo 4, às realizações de $C \hat{E}$, Cê e $S e$ depois de verbo. Para cada grupo, temos os números das sentenças correspondentes, conforme numeração do experimento mostrado acima, um trecho da realização dessas sentenças e os respectivos valores para a duração e a intensidade. Ressalte-se que nem sempre as realizações das formas correspondem ao que está escrito nas sentenças, pois, como dito anteriormente, utilizamos alguns recursos para obter as reduções, ou seja, esperava-se que as formas Eles e Não fossem pronunciadas como Ez e $N u m$ nas velocidades rápida e rapidíssima, como explicado mais acima.

\begin{tabular}{|c|c|c|c|c|}
\hline \multicolumn{5}{|c|}{ Médias } \\
\hline Grupos & No Sentença & Realização & $\begin{array}{c}\text { Duração } \\
\text { (ms) }\end{array}$ & $\begin{array}{c}\text { Intensidade } \\
\text { (db) }\end{array}$ \\
\hline \multirow[t]{5}{*}{1} & 02 & ...eles falou... & 285.6 & 54.6 \\
\hline & 02 & ...ez falou... & 153.8 & 56.4 \\
\hline & 7 e 13 & ...eles diz/disse... & 287.1 & 56.7 \\
\hline & 7 e 13 & ...ez diz/disse... & 165.7 & 59.3 \\
\hline & 12 & ..ex $\operatorname{diz} .$. & 185.2 & 58.6 \\
\hline \multirow[t]{4}{*}{2} & 10 & ...não falou... & 179.8 & 51.7 \\
\hline & 10 & ...num falou... & 101.7 & 55.9 \\
\hline & 3 & ...não disse... & 171.7 & 54.9 \\
\hline & 3 & ...num disse... & 128.9 & 56.5 \\
\hline \multirow[t]{4}{*}{3} & 9 & ...CE (Cecília) falou... & 222.6 & 57.9 \\
\hline & 5 & ...ce (pronome) falou.. & 152.5 & 55.9 \\
\hline & 1 & ...CE (Cecília) disse... & 271.7 & 56.1 \\
\hline & 4 & ...ce (pronome) disse.. & 224.9 & 56.5 \\
\hline \multirow[t]{3}{*}{4} & 6 & vestiu CE (Cecília).. & 233.4 & 56.6 \\
\hline & 11 & vestiuCe (pronome) & 204.9 & 54.9 \\
\hline & 8 & ...vestiu-se.... & 132.9 & 54.9 \\
\hline
\end{tabular}

Tabela 1: Médias da intensidade(dB) e da duração(ms) para as partículas estudadas 


\subsection{Análise dos valores obtidos para a duração (ms)}

Analisando os valores para a duração, os resultados vieram ao encontro da nossa hipótese de que podemos atestar, foneticamente, as formas reduzidas. É importante ressaltar que não tínhamos a pretensão de identificar essas formas reduzidas marcadamente como clíticos, pensamos apenas que existe, para estas partículas, um processo em andamento. Talvez elas sejam, por ora, apenas formas fracas, e pode ser que venham a incorporar características de clíticos verdadeiros. Enquanto isso, nosso estudo tenta identificar esse comportamento fonético das reduções do português brasileiro.

O que verificamos foi uma gradação da duração entre as partículas que usamos para a comparação. Observemos agora, mais detalhadamente, os resultados aferidos acerca da duração. A Tabela 2 abaixo, novamente organizada em grupos de sentenças para efeito de comparação entre elas, nos permite visualizar melhor a gradação dos valores entre as formas plenas e as reduzidas. Infelizmente, por nosso experimento ainda não se encontrar completo, restando algumas gravações a serem feitas, não poderemos estender a análise seguinte às realizações de Eles, Ez e Ex. Podemos apenas considerar aqui a gradação da duração para essas partículas de forma global, como mostrado na Tabela 1. No entanto, uma análise mais detalhada como a que se segue não será possível para essas palavras devido à falta de dados dessas partículas seguidas de sílabas átonas. Colocaremos os dados das partículas Eles, Ez e Ex seguidas de sílaba tônica apenas como dado adicional. Portanto, voltemos agora à análise mais detalhada das medidas para as partículas Não, Num, Ĉ, Cê, e Se. 


\begin{tabular}{|c|l|c|}
\hline Grupo & Realização + Ambiente & Duração (ms) \\
\hline \multirow{2}{*}{1} & Eles + sílaba tônica & 287,1 \\
\cline { 2 - 3 } & Ex + sílaba tônica & 185,2 \\
\cline { 2 - 3 } & Ez + sílaba tônica & 165,7 \\
\hline \multirow{2}{*}{2} & Não + sílaba átona & 179,8 \\
\cline { 2 - 3 } & Num+ sílaba átona & 101,7 \\
\hline \multirow{2}{*}{3} & Não + sílaba tônica & 171,7 \\
\cline { 2 - 3 } & Num + sílaba tônica & 128,9 \\
\hline \multirow{2}{*}{4} & Ce (nome) + sílaba átona & 222,6 \\
\cline { 2 - 3 } & Ce (pronome) + sílaba átona & 152,5 \\
\hline \multirow{2}{*}{5} & Ce (nome) + sílaba tônica & 271,7 \\
\cline { 2 - 3 } & Ce (pronome) + sílaba tônica & 224,9 \\
\hline
\end{tabular}

Tabela 2: Duração(ms) das partículas conforme ambiente fonético.

Como podemos observar, obtivemos uma gradação dos valores para todos os segmentos analisados e, em todos os cinco grupos, a forma plena Não a partícula $C \hat{E}$, significando nome próprio, mostraram uma duração maior do que suas respectivas formas reduzidas, estando sempre nos mesmos ambientes. Nos grupos 1 e 2, por se tratar de um dissílabo, é provável que o pronome Eles teria maior duração do que sua redução $E z$, mas não se trata apenas de uma questão silábica; pois, como os dados apontam, a redução $E z$ possui, ainda assim, uma menor duração do que o também monossílabo $E x$.

Outro importante fato observado foi a constância de uma maior diferença entre os valores medidos para a duração em ambiente "partícula + sílaba tônica". Examinando-se os grupos 1, 2 e 3, 4 e 5, observa-se em todos uma gradação dos valores da duração atestando um processo de cliticização para as formas reduzidas. Mas, em 2 e 4, onde o ambiente é "partícula + sílaba átona", a diferença de duração é maior do que em 3 e 5 , cujo contexto é "partícula + sílaba tônica". Embora as reduções também possuam menor duração ocorrendo no contexto das sentenças 2 e 4, esse valor é ligeiramente maior do que no contexto das sentenças 3 e 5 . O quadro dessas diferenças em contexto tônico/átono é o seguinte: no grupo 2 , onde 
a sílaba seguinte à partícula é átona, o intervalo entre Não e Num foi aproximadamente $78 \mathrm{~ms}$ (diferença entre os valores $179.8 \mathrm{~ms}$ para Não e 101.7 ms para Num), enquanto para o grupo 3, onde a sílaba seguinte à partícula é tônica, a diferença foi de, aproximadamente, 43 ms. O mesmo ocorreu para os grupos 4 e 5 . Em 4, a diferença é de $71 \mathrm{~ms}$ para a duração entre as formas plena e reduzida e de 47 ms em 5 . Esse fenômeno ocorreu na totalidade de nossos dados.

Recorrendo à literatura, encontramos uma explicação condizente e possível para esse fenômeno, na estruturação rítmica do português. Sendo uma língua de ritmo acentual, é provável que o pé métrico seja uma unidade que exerça uma influência sobre a organização temporal dos enunciados. Observemos, por exemplo, as sentenças 3 e 10 (vide experimento no item 2 deste artigo) e suas duas realizações efetuadas, com a marcação dos pés métricos (entre barras) de cada uma mostrada abaixo:

Sentença 03: /Diga/Jô não /disse nada/ não.

Ou:/Diga/ Jô num /disse nada/ não.

Sentença 10: /Diga/Jô não fa/lou nada/ não.

Ou:/Diga/ Jô num fa/lou nada/não.

Essas duas sentenças estão aqui mostradas cada uma em suas duas realizações ocorridas. A sentença 3 foi realizada de duas formas: uma com a partícula estudada em sua forma plena, isto é, Não, e outra com a partícula em sua respectiva forma reduzida, isto é, Num. O mesmo pode ser dito para a sentença 10, mostrada logo abaixo da sentença 3. Para a análise que se segue, o segundo pé métrico ou a segunda é o que interessa.

Cada pé métrico das sentenças acima compreende uma sílaba tônica e as sílabas átonas que se seguem até a sílaba tônica seguinte, quando um novo pé métrico se inicia.

No estudo do ritmo, é conhecida a noção de isocronia, na qual os pés métricos tendem a ter a mesma duração, ou seja, essa é uma propriedade em que o tempo de realização dos pés métricos de uma frase tende a ter a mesma duração. Isso não quer dizer que um pé 
com duas sílabas terá a mesma duração que um pé com uma ou três sílabas, mas que os valores para a duração dos mesmos tendem a se aproximar. Comparando-se o segundo pé métrico de cada uma das sentenças 3 e 10 entre si, em 10 o número de sílabas no segundo pé é maior, tanto para a ocorrência com forma reduzida quanto para a ocorrência com forma plena: a sentença 10 tem três sílabas métricas em seu segundo pé enquanto que a sentença 3 tem apenas duas. Tendo em vista o princípio de isocronia, os pés das sentenças tendem a ser proferidos no mesmo tempo. Conseqüentemente, o segundo pé métrico da sentença10, que contém três sílabas, terá uma duração semelhante ao pé métrico da sentença 3, só que dividida pelas suas três sílabas. Isso provavelmente explica o fato de a duração das partículas reduzidas ser menor antes de sílaba átona do que antes de sílaba tônica. No entanto, é importante dizer que o princípio de isocronia funciona no interior de cada enunciado. Como as condições experimentais nos levam a crer que a organização temporal desses enunciados é a mesma, pensamos que a hipótese, neste estudo preliminar, do efeito do ritmo pode fornecer uma primeira explicação.

Em ambiente pós-verbal, as partículas $C \hat{E}$, Cêe Se obtiveram as seguintes medições para a duração, como mostrado na tabela 3:

\begin{tabular}{|c|c|c|}
\hline Ambiente & Partícula & Duração (ms) \\
\hline \multirow{3}{*}{ Pós-Verbal } & CÊ (nome) & 233,4 \\
\cline { 2 - 3 } & Cê (pronome) & 204,9 \\
\cline { 2 - 3 } & Se (reflexivo) & 132,9 \\
\hline
\end{tabular}

Tabela 3: Duração(ms) das partículas $C \hat{E}$, Cêe $S e$ em ambiente pós-verbal.

Aqui observamos, novamente, a gradação da duração entre a forma não clítica $C \hat{E}$, a forma reduzida $C \hat{e}$ e a forma clítica $S e$.

\subsection{Análise dos valores obtidos para a Intensidade (dB)}

Já a intensidade parece não distinguir as formas plenas das formas reduzidas da mesma maneira como obtivemos com o 
parâmetro da duração. O esperado, seguindo a análise da duração, seriam valores menores aferidos para a intensidade das formas reduzidas do que para as formas plenas, aproximando as reduções ao pronome clítico Se e atestando o processo de cliticização proposto por Vitral. No entanto, o que ocorreu parece não corroborar esse processo de cliticização. Observou-se $e^{5}$ que a intensidade parece estar, na verdade, compensando a duração; numa comparação entre formas plenas e reduzidas. Vejamos novamente os valores para a intensidade, em contraste com os valores para a duração, das formas plenas e de suas respectivas formas reduzidas na tabela 4 . Observe que retiramos as comparações entre $C \hat{E}$ (Cecília) e $C \hat{e}$ (pronome), pois estas não são partículas concorrentes, ou seja, a primeira não corresponde à redução da segunda, tal qual Eles e Ez. Assim, a tabela 4 nos dá o contraste entre a duração e a intensidade numa comparação entre formas plenas e suas respectivas formas reduzidas.

\begin{tabular}{|c|c|c|}
\hline Realização & Duração (ms) & Intensidade (dB) \\
\hline$\ldots$.eles falou... & 285.6 & 54.6 \\
\hline ..ez falou... & 153.8 & 56.4 \\
\hline ..eles diz/disse... & 287.1 & 56.7 \\
\hline ..ez diz/disse... & 165.7 & 59.3 \\
\hline ...ex diz... & 185.2 & 58.6 \\
\hline ...não falou... & 179.8 & 51.7 \\
\hline ...num falou... & 101.7 & 55.9 \\
\hline ...não disse... & 171.7 & 54.9 \\
\hline ...num disse... & 128.9 & 56.5 \\
\hline
\end{tabular}

Tabela 4: Contraste entre duração e intensidade das formas concorrentes.

A partir dos dados da tabela 4 , observamos o seguinte fenômeno: a intensidade parece compensar a duração na medida em que esses parâmetros se mostram em distribuição inversamente proporcional. Vejamos as partículas Eles e Ez; a duração da forma plena Elesé de 285.6 ms (antes de sílaba átona) e de 287.1 ms (antes de sílaba tônica); e sua intensidade é de $54.6 \mathrm{~dB}$ (antes de sílaba átona) e 56.7 dB (antes de sílaba tônica). Para sua forma reduzida $\mathrm{Ez}$, 
a duração cai para 153.8 ms (antes de sílaba átona) e para $165.7 \mathrm{~ms}$ (antes de sílaba tônica) enquanto que a intensidade sobe para 56.4 dB (antes de sílaba átona) e para $59.3 \mathrm{~dB}$ (antes de sílaba tônica). Isto é, foneticamente, essa redução da duração é compensada na intensidade. O mesmo ocorre para Não e Num, basta observarmos a tabela acima.

Portanto, duração e intensidade apresentam comportamento diverso nos contextos forma plena/forma reduzida.

\section{CONCLUSÕES}

Iniciamos este trabalho com o objetivo de atestar, foneticamente, as formas reduzidas do português brasileiro $E z, N u m$ e Cê e com a hipótese de que haveria, para estas reduções, um processo de cliticização, como proposto por Vitral.

Através da análise, vimos que esse processo de cliticização pode ser confirmado tanto pelo parâmetro da duração como da intensidade. Pudemos, assim com essa análise, atestar foneticamente as reduções de Eles, Não e Você.

Portanto, as reduções do português brasileiro aqui estudadas possuem as seguintes características fonéticas: há, para as partículas Ez, Num e Cêuma menor duração em comparação com as formas plenas Eles e Não e com a partícula correspondente a Cêe, marcadamente não clítica, $C \hat{E}$ (significando nome próprio); e maior intensidade numa comparação apenas entre formas reduzidas e respectivas formas plenas (excetuando-se aí $C \hat{E}$ (Cecilia) e $C \hat{e}$ (você) pois não são partículas concorrentes tal qual Elese Ez ou Não e Num), o que nos leva a concluir que talvez a queda constatada na duração das formas reduzidas estaria sendo compensada pela intensidade. Trata-se, no entanto, de estudo preliminar, que merecerá desenvolvimentos posteriores.

No entanto, reconhecemos que este trabalho conta com poucos dados numéricos para tirarmos maiores conclusões para o processo de cliticização proposto por Vitral. Por ora, pudemos atestar as formas reduzidas e elucidar alguns aspectos de seu comportamento fonético. 


\section{NOTAS}

${ }^{1}$ Essas variáveis sócio-culturais não serão analisadas neste trabalho.

${ }^{2}$ Tivemos o cuidado de que a partícula $E x$ fosse assim realizada, i. e., não nos interessava, nem fazem parte deste estudo, realizações desta partícula como a forma ditongada Eix.

${ }^{3}$ As sentenças que contêm o pronome Eles se encontram com o verbo no singular e o sujeito no plural de propósito. Este foi mais um recurso utilizado a fim de se obter a redução $E z$.

${ }^{4}$ Como dito na introdução, clíticos e, conseqüentemente, formas reduzidas não ocorrem como elemento pós-verbal numa proposição quando não possuem um hospedeiro no qual possam se ancorar. É importante frisar que isso não ocorre em nosso experimento, porque, embora na sentença 11, "Diga o estilista vestiu Cê bem", por exemplo, a partícula Cê esteja em ambiente pós-verbal, seu hospedeiro é o advérbio bem. Segundo a sintaxe gerativa, a partícula Cê forma uma oração reduzida onde Cê é o sujeito e bem o predicado.

${ }^{5}$ Observação feita pelo Prof. José Olímpio de Magalhães.

\section{REFERÊNCIAS BIBLIOGRÁFICAS}

BRANDÃO DE CARVAlHO, J. Phonological conditions on Portuguese clitic placement: on syntactic evidence for stress and rhythimical patterns. Linguistics 27, p. 405-436, 1989.

CAGLIARI, L. C. Algumas considerações sobre a duração silábica. Um estudo com dados do Projeto de Gramática do Português Falado. Campinas: Unicamp. IEL, 1993.

CORRÊA, L. T. A forma clítica de pronome pessoal no dialeto mineiro: uma variante sociolingüistica. 1998. Dissertação (Mestrado em Estudos Lingüísticos) - Faculdade de Letras da UFMG.

DELGADO-MARTINS, M. R. Ouvir falar. Introdução à fonética do português. Caminho: Lisboa, 1988. Cap. 2, 3, 5 e 6.

FERNANDES, N. Contribuição para uma análise instrumental da acentuação $e$ intonação do português. 1976. Dissertação (Mestrado) - USP, São Paulo.

JASSEM, W. The phonology of modern English. Warszawa: Panstwowe Wydawnictwo Naukowe, 1987. 
JOHNSON, K. Acoustic and auditory phonetics. Malden, MA-USA: Blackwell Publishing, 2003.

MORAES, J. A. de. Acentuação lexical e acentuação frasal em português. Um estudo acústico-perceptivo. Estudos Lingüísticos e Literários, n. 17, Universidade Federal da Bahia, p.39-57, jul. 1995.

RAMOS, J. O uso das formas Você, Ocê e Cê no dialeto mineiro. In: DA HORA (Ed.). Diversidade Lingüistica no Brasil, 1997. p.43-60.

VITRAL, L. T. A forma Cê e a noção de gramaticalização. Revista de Estudos da Linguagem, n. 5, p.115-124, 1996.

VITRAL, L. T. Identifying clitics: phonetic evidence. Artigo inédito, UFMG, 2001.

VITRAL, L. T.; RAMOS. J. Gramaticalização de "você": um processo de perda de informação semântica? Filologia e Lingüistica Portuguesa, Humanitas Publicações, São Paulo, v.3, p.55-64, 1999. 